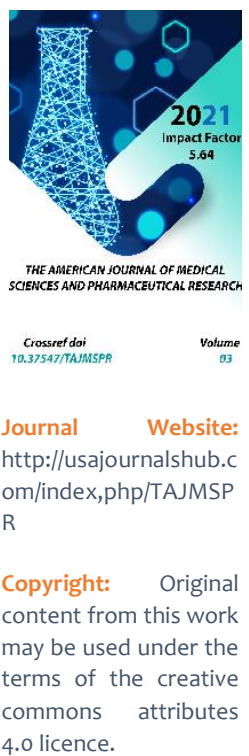

\section{The late diagnosis of hemochromatosis in the patient with chronic hepatitis B and kidney damage Clinical Case Report}

O.V.Skosireva

Department Of Faculty Internal Diseases, Tashkent State Dental Institute, Tashkent, Republic Of Uzbekistan

M.O.Sobirov

Department Of Faculty Internal Diseases, Tashkent State Dental Institute, Tashkent, Republic Of Uzbekistan

L.T.Daminova

Department Of Faculty Internal Diseases, Tashkent State Dental Institute, Tashkent, Republic Of Uzbekistan

S.U.Muminova

Department Of Endocrinology, Tashkent Pediatric Medical Institute, Tashkent, Republic of Uzbekistan

\title{
ABSTRACT
}

A late diagnosis of secondary hemochromatosis was made to a 38-year-old man with chronic hepatitis $\mathrm{B}$, who after poisoning with alcohol surrogate (which was a year ago) had episodes of macrohematuria with signs of acute kidney damage, which required treatment in the ICU and hemodialysis sessions, after which kidney function was restored. In August 2020, the patient had a contact with a COVID-19 patient, but upon admission to the hospital, the results of tests for COVID-19 were negative. During the examination in our department, after the exclusion of the urological disease, the diagnosis of interstitial nephritis of toxic etiology, hemolytic anemia, chronic viral hepatitis B was made. Then indepth study of iron metabolism, bone marrow, and MRI of parenchymal organs revealed secondary hemochromatosis.

\section{KEYWORDS}

COVID-19, ICU, Physical examination, diagnosis

\section{INTRODUCTION}

Primary or secondary excessive accumulation of iron in a human body can be genetic or acquired. Both these conditions are known to result in organ damage with clinical symptoms 
of cirrhosis, diabetes mellitus, arthritis, endocrine abnormalities and cardiomyopathy.[1] The normal amount of total body iron in adults is 3-4 g; however, there are some pathologic conditions that lead to iron overload because there is no mechanism removing excessive iron from the body. In many patients, the symptoms appear between 30-60 years of age. According to some researchers, the onset of the disease in men occurs usually earlier than in women [2].

In hereditary hemochromatosis, excessive iron is primarily deposited in the parenchymal cells, whereas in hemochromatosis associated with blood transfusion, it is primarily accumulated in the reticuloendothelial cells. The abnormal amount of iron is deposited in the cells as hemosiderin. This inevitably results in the cell death and replacement of these cells by a fibrous deposition that leads to destruction and/or impairment of organ function [3].

Without treatment, the disease can progress to life-threatening complications. It is not easy to diagnose hemochromatosis because the disease is rare and manifests itself by various symptoms.

\section{CASE PRESENTATION}

A 38-year-old man was admitted to the hospital of Tashkent Medical Academy (TMA) on 30.11.2020 with complaints of red urine, jaundice of the skin and visible mucous membranes, lower back pain, lack of appetite, headache, dizziness, DOE, and pronounced general weakness. He is married, lives in an apartment with his family; at present he does not work due to hemodialysis sessions. None of his alive relatives has the complaints that he describes.
History of the present illness. The patient thinks that he has been ill for one year. In October 2019, he was hospitalized in the ICU with the symptoms of alcohol surrogate intoxication; later on he was treated at the therapeutic department of the medical setting at the place of residence. One day he noticed that his urine turned red. The second episode of red urine for no apparent cause was in April 2020. For this reason, he received the outpatient treatment (there is no hx of the diagnosis and treatment), after which the color of the urine returned to normal. In August 2020, after a contact with a COVID-19 patient, he felt fever and his urine output decreased, the lower back pain returned, and his appetite decreased; in addition, he had headache, dizziness, shortness of breath on light physical exertion, and pronounced general weakness. He reported smoking five packs of tobacco a week and drinking beer almost every evening. The patient denies any severe chronic disease in his family-members and close relatives.

At the ICU his the creatinine level was dramatically output $1,200 \mu \mathrm{mol} / \mathrm{l}$; therefore, he received 5 sessions of hemodialysis, after which the urine output restored; his symptoms significantly regressed, and the creatinine level reached the normal values. However, two months later, the urine output again dropped, his urine turned red; the creatinine level was over $700 \mu \mathrm{mol} / \mathrm{l}$. On this occasion, the patient again received 3 sessions of hemodialysis followed by improvement of his general condition and normalization of creatinine level. However, later, for no apparent cause, the patient has noticed redness of his urine again, jaundice of the skin and visible mucous membranes, low back pain, headache, dizziness, lack of appetite, increased shortness of breath on light physical exertion and general 
weakness. He was hospitalized into the Nephrology Department of the TMA hospital.

\section{PHYSICAL EXAMINATION}

On obtaining the written consent, the patient was thoroughly examined. The general condition of the patient was of moderate severity; he was alert and fully oriented, afebrile and semi-active; the skin and visible mucous membranes were icteric; the skin turgor was reduced; there was no peripheral edema, and his subcutaneous fat was moderately developed, his body mass index was $23 \mathrm{~kg} / \mathrm{m} 2$ The joints were without visible changes, painless on palpation and moved in full range. The muscles were painless on palpation; the muscle force was normal. The peripheral lymph nodes were not enlarged, painless. The chest was cylindrical and painless when palpated, and participated in breathing evenly. His respiratory rate was 22 breaths per minute with oxygen saturation 98\%. Percussion revealed a clear pulmonary sound over the lungs, auscultation found out vesicular breathing. The heart area had no peculiar features. The borders of the relative cardiac dullness were found $1.5 \mathrm{~cm}$. medially of the midclavicular line in the 5 th intercostal space; the heart tones were slightly muted, rhythmic, the pulse was $88 \mathrm{bpm}$., rhythmic, of medium filling and tension; the blood pressure was $130 / 80 \mathrm{~mm} \mathrm{Hg}$ on both hands. The tongue was moist, thickly covered with a white coat. The anterior abdominal wall was symmetrical, soft, and painful on palpation in the right hypochondrium. The liver was felt $1 \mathrm{~cm}$ below the costal margin, slightly compacted, sensitive to palpation; the spleen is enlarged $(14,8 \mathrm{~mm} \times 5,8 \mathrm{~mm})$. The gallbladder was not palpable, and the gallbladder symptoms were negative. The patient told that he had constipation rather often. The lumbar region on examination showed no specific features though was painful on palpation; the costovertebral angle areas were painful on both sides. His urination was regular; the daily diuresis was about $1000 \mathrm{ml}$. The laboratory test results before and during the treatment are given below (Table 1).

Table 1. Laboratory data before and during treatment

\begin{tabular}{|c|c|c|c|}
\hline Component & Standard range & $\begin{array}{c}\text { Before } \\
\text { treatment }\end{array}$ & $\begin{array}{l}\text { On day } 7 \text { of } \\
\text { treatment }\end{array}$ \\
\hline \multicolumn{4}{|c|}{ Blood } \\
\hline Hemoglobin & $130-160 \mathrm{~g} / \mathrm{l}$ & 72.0 & 84 \\
\hline Red blood cells & $4.0-5.010 \times 12 / 1$ & 2.8 & $3 \cdot 3$ \\
\hline Color index & $0.85-1.05$ & 0.7 & 0.8 \\
\hline Hematocrit & $41-53 \%$ & 29 & 25 \\
\hline Reticulocytes & $0.2-1.2 \%$ & 11.4 & 10.6 \\
\hline White blood cells & $4.0-9.0 \quad 10 \times 3 / 1$ & 9.0 & 14.0 \\
\hline Platelet count & $180.0-320.010 \times 3 / 1$ & 208 & 182 \\
\hline ESR & $2-10 \mathrm{~mm} / \mathrm{h}$ & 45 & 30 \\
\hline $\begin{array}{l}\text { Notes to the complete } \\
\text { blood cell count }\end{array}$ & & $\begin{array}{c}\text { Evident } \\
\text { anisocytosis }\end{array}$ & $\begin{array}{c}\text { Evident } \\
\text { anisocytosis }\end{array}$ \\
\hline Blood clotting time & $3-5 \mathrm{~min}$ & $3.10-3.25$ & $3.60-4.55$ \\
\hline ALT & $0-40.0 \mathrm{U} / \mathrm{I}$ & 67 & 28 \\
\hline
\end{tabular}


The American Journal of Medical Sciences and Pharmaceutical Research

(ISSN - 2689-1026)

Published: April 30, 2021 | Pages: 59-67

IMPACT FACTOR

2021: 5.64

Doi: https://doi.org/10.37547/TAJMSPR/Volume03Issue04-09

OCLC - 1121105510

\begin{tabular}{|c|c|c|c|}
\hline AST & $0-40.0 \mathrm{U} / \mathrm{l}$ & 80 & 24 \\
\hline LDG & $120-240 \mathrm{U} / \mathrm{I}$ & 937 & 875 \\
\hline Total bilirubin & $3.4-20.5 \mu \mathrm{mol} / \mathrm{l}$ & 65.7 & 35.1 \\
\hline Conjugated bilirubin & $0,86-5,3 \mu \mathrm{mol} / \mathrm{l}$ & 21,3 & 10,1 \\
\hline Unconjugated bilirubin & $1.7-17.1 \mu \mathrm{mol} / \mathrm{l}$ & 44.4 & 25.0 \\
\hline Total protein & $65-85 \mathrm{~g} / \mathrm{l}$ & 59,0 & 64,1 \\
\hline Serum iron & $11.6-31.3 \mu \mathrm{mol} / \mathrm{l}$ & 41.2 & $35 \cdot 3$ \\
\hline Ferritin & $20-250 \mu \mathrm{g} / \mathrm{i}$ & 420.1 & 338.2 \\
\hline $\begin{array}{l}\text { Iron-binding capacity of } \\
\text { serum }\end{array}$ & $45-75 \mu \mathrm{mol} / \mathrm{l}$ & 16.2 & 15.8 \\
\hline Transferrin & $25-45 \mu \mathrm{mol} / \mathrm{l}$ & 13.7 & 14.9 \\
\hline Haptoglobin & $450-1650 \mathrm{mg} / \mathrm{l}$ & 305 & 315 \\
\hline Fibrinogen & $2-4 g / 1$ & 4.13 & 3.15 \\
\hline Prothrombin index & $80-100 \%$ & 105 & 90 \\
\hline $\begin{array}{l}\text { International normalized } \\
\text { ratio }\end{array}$ & $<1.0$ & 1.2 & 1.0 \\
\hline \multicolumn{4}{|c|}{ Urine } \\
\hline Specific gravity & $1012-1020 \mathrm{~kg} / \mathrm{l}$ & 1016 & 1020 \\
\hline Protein & no & 1.98 & 1.32 \\
\hline Urobilinogen & no & positive & positive \\
\hline Epithelium & $1-2-3$ & $1-2-3$ & $0-1-3$ \\
\hline WBC & $0-3$ & $20-23-28$ & $10-20-25$ \\
\hline RBC & $0-0-1$ & $\begin{array}{c}\text { unmodified } \\
\text { 6-10-15 } \\
\text { modified } 4-6-8 \\
\end{array}$ & $\begin{array}{c}\text { unmodified } \\
\text { 6-8-8 } \\
\text { modified } 4-8-8 \\
\end{array}$ \\
\hline Casts & no & grainy $1-3-3$ & grainy $0-1-3$ \\
\hline Mucus & no & $(++)$ & $(++)$ \\
\hline Bacteria & no & $(+++)$ & $(++)$ \\
\hline \multicolumn{4}{|c|}{ Mid-stream clean catch sample } \\
\hline WBC per $1 \mathrm{ml}$ & $<4000$ & 16000 & 2200 \\
\hline $\mathrm{RBC}$ per $1 \mathrm{ml}$ & $<1000$ & 10000 & 1050 \\
\hline Active WBC per $1 \mathrm{ml}$ & abs & abs & abs \\
\hline Casts per $1 \mathrm{ml}$ & $<24$ & $8-9$ & $1-3$ \\
\hline
\end{tabular}

The bacteriological culture of urine detected $E$. Coli (5000 000 per $1 \mathrm{ml}$ ). The sample showed the maximum sensitivity to ceftriaxone. The myelogram revealed moderate hyperplasia of the erythroid progenitor with the normoblastic hematopoiesis. ELISA for AT HBs to hepatitis B virus $(+)$. HBV PCR (+). Instrumental examination

ECG: Sinus tachycardia, the rhythm is correct; HR 104 bpm; the electric axis of the heart is not deviated. The heart is in the intermediate position. When combined with the clinical symptoms, one can think of left ventricular 
hypertrophy. Ureterorenoscopy: hypospadias hematuria due to bleeding in the upper urinary tract.

Ultrasound examination of the liver, gallbladder, pancreas, spleen and kidneys: there are signs of a moderate increase in echogenicity of the liver parenchyma with mild hepatomegaly, calculous cholecystitis, moderate splenomegaly, signs of chronic nephritis.

Kidney biopsy: flat refusal

MSCT: signs of chronic calculous cholecystitis, moderate splenomegaly, and diffuse iron accumulation in the liver, spleen, and kidney cortex (see below).
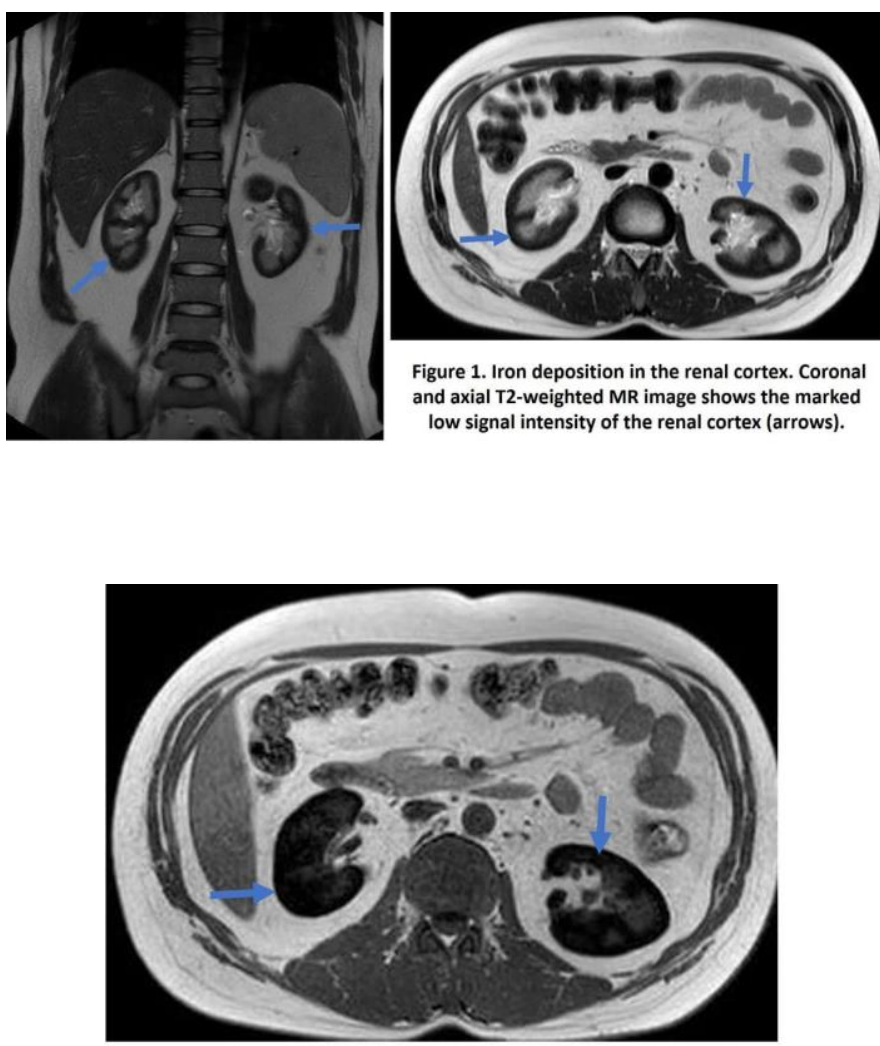

Figure 2. Iron deposition in the renal cortex. Axial T1weighted MR image shows marked hypointense signal of renal cortex (arrows). 

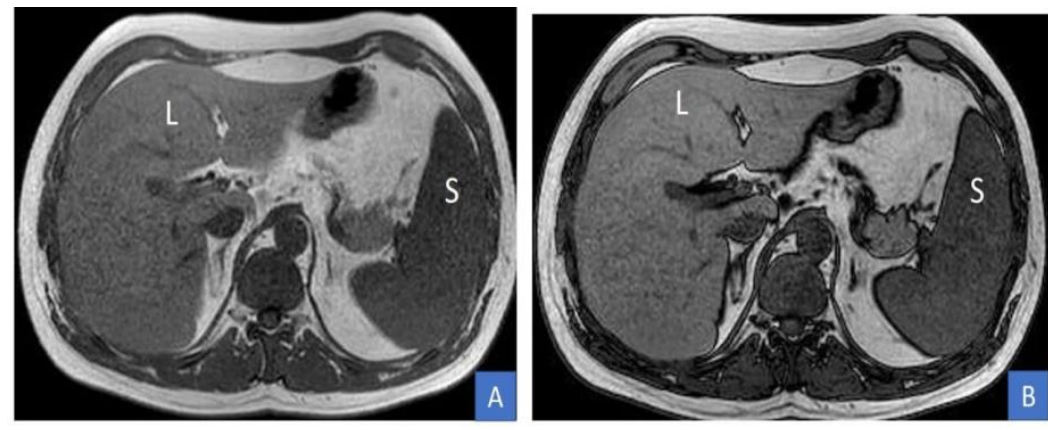

Figure 3. Iron deposition in the liver (L) and the spleen (S). Axial T1-weighted in-phase MR image $(A)$ shows the slightly low signal intensity of the liver and the spleen compared to axial T1-weighted out-of-phase MR image (B).

The principal clinical diagnosis, i. e. chronic tubulointerstitial nephritis (according to ICD X - N 11.8), CKD stage I, was made on the basis of the red urine episodes and the signs of acute kidney damage that necessitated hemodialysis sessions, the information on chronic viral hepatitis $B$ and severe alcohol surrogate poisoning in the patient's history, some objective signs (the yellow skin and mucous membranes, hepato- and splenomegaly), laboratory signs: hypochromic anemia, reticulocytosis, accelerated ESR, higher levels of transaminases and lactate dehydrogenase, bilirubin (mainly due to the indirect fraction), serum iron, ferritin with a simultaneous decrease in total protein, haptoglobin, transferrin, iron-binding ability of serum, as well as the presence of proteinuria, leukocyturia, erythrocyturia, cylindruria and bacteriuria revealed by the complete urinalysis; in the mead-stream urine catch, a significant increase in the WBC and RBC counts; the bone marrow picture (erythroid germ hyperplasia with the normoblastic type of hematopoiesis); the instrumental examination findings: ultrasound - the signs of increased echogenicity of the liver parenchyma with hepatomegaly, calculous cholecystitis, splenomegaly, signs of chronic nephritis;
MSCT: signs of chronic calculous cholecystitis, moderate splenomegaly, diffuse iron accumulation in the liver, spleen, renal cortex.

The competing diseases are hemolytic anemia grade 2, secondary hemochromatosis; the concomitant diseases are chronic primary pyelonephritis in the stage of active inflammation, chronic viral hepatitis B of minimal activity, cholelithiasis, calculous cholecystitis.

The following treatment was performed:

$1,000 \mathrm{mg}$ of solu-medrol $+50,000$ units of heparin $+200 \mathrm{ml}$ of $0.9 \%$ saline by IV dripinfusion for 3 consecutive days,

$1000 \mathrm{mg}$ of ceftriaxone $+10 \mathrm{ml}$ of $0.9 \%$ saline IV twice a day (after the test) for 7 days,

$200 \mathrm{ml}$ of $0.05 \%$ pentoxifylline by IV injection for 3 and 7 days, $4.2 \%$ arginine - by 5 IV dripinfusions,

$3 \mathrm{ml}$ of 10\% acetylcysteine, IM twice a day for 5 days,

Ferrum-lek $2.0 \mathrm{v} / \mathrm{m}$, deep IM once a day, 
200 reosobilact by IV drip-infusion once in 3 days,

$400 \mathrm{mg}$ of ademetionine $+50 \mathrm{ml}$ of $0.9 \%$ saline by IV drip-infusion once a day for 5 days,

$1,200 \mathrm{mg}$ of glutathione $+50 \mathrm{ml}$ of $0.9 \%$ saline by IV drip-infusion once a day, $\quad 5 \mathrm{mg}$ of prednisolone from day 4 of treatment (after solumedrol), 6 tab/day according to protocol,

$25 \mathrm{mg}$ of dipyridamole, 2 tablets 3 times a day.

After the seven-day treatment the patient's general condition improved somewhat: lower back pain and general weakness decreased. The appetite improved.

According to the clinical diagnosis the patient was referred to the Research Institute for Hematology and Blood Transfusion for further treatment with the recommendation to continue the treatment with the following drugs for one month: $5 \mathrm{mg}$ prednisolone, 14 tablets according to the protocol,

25 mg dipyridamole, 2 tablets 3 times a day,

Ursodeoxycholic acid, $1000 \mathrm{mg} /$ day,

Alpha-tocopheryl acetate, $200 \mathrm{mg} /$ day,

Iron sulfate with vitamins, 1 capsule twice a day,

The therapy should be followed by one more examination by a nephrologist and acomplete analysis of urine, urea and creatinine.

\section{DISCUSSION}

This clinical case is of interest in terms of late diagnosis of hemochromatosis, that, most likely, was associated with the manifestation of the disease by symptoms generated by the kidneys and urinary tract in the form of episodes of macrohematuria and the signs of acute kidney damage which required hemodialysis sessions. When an urological disease was excluded, the diagnosis of chronic tubulointerstitial nephritis was made taking into account persistent changes in the patient's urine as well as the history of severe alcohol poisoning against the background of chronic viral hepatitis B. However, the presence of anemia, the nature and severity of which were not typical for such kidney damage, required further diagnostic search.

An increase in the level of transaminases, LDH, total bilirubin owing to its indirect fraction, serum iron, and ferritin levels with a simultaneous decrease in total protein, haptoglobin, transferrin, serum iron-binding capacity, as well as the characteristic picture of the bone marrow, i.e. erythroid germ hyperplasia in normoblastic type of hematopoiesis, indicated clearly the hemolytic nature of anemia. The MRI examination (cholelithiasis, iron deposits in the liver, spleen and kidney cortex) allowed us to diagnose hemochromatosis with a sufficiently high confidence.

Hemochromatosis was described for the first time in 1871 as a symptom complex that included cirrhosis of the liver, diabetes mellitus and an unusual bronze color of the skin. On the basis of these data, an independent nosological unit "hemochromatosis" was introduced in 1889. This so-called "general hemosiderosis" is a secondary condition associated with intravascular hemolysis of red blood cells in anemia, leukemia, hemolytic poisons, transfusion of blood of an inadequate group, infectious diseases (including hepatitis 
$B$ and $C$ viruses), drug and food poisoning, alcoholism[3].The literature describes cases of hemosiderosis of the kidneys as a complication of sickle cell [4].

At the first stage, an excessive accumulation of hemosiderin develops in the reticular and endothelial cells of the liver, spleen, lymph nodes and bone marrow; later on it occurs in the cells of the kidneys, lungs, etc. Simultaneously, bilirubin accumulates with the development of hemolytic jaundice in patients and gallstones formation. The researchers found that a kidney damage occurred only in intravascular hemolysis and the mechanism of iron accumulation was associated with the release of free hemoglobin into the plasma. With prolonged hemolysis, the amount of free hemoglobin increases and its excessive amount in the plasma is filtered through the glomeruli, and then it is reabsorbed and degraded in the epithelial cells of the proximal tubules of the nephron. Iron in hemosiderin can cause the formation of free radicals with the activation of lipid peroxidation, which damages the tubules causing their necrosis and interstitial fibrosis. [5 ]. At the same time, it is known that the renal type of iron accumulation is observed only in cases of intravascular hemolysis of red blood cells with deposition of hemosiderin in the proximal convoluted tubules causing a decrease in the MR signal from the cortical substance, which was revealed during such examination in this patient. $\mathrm{MRI}$ is considered a highly informative method of radiological diagnosis of renal hemosiderosis and demonstrates the absence of a clear correlation between the preservation of global renal functions and the degree of severity of changes obtained with the help of such a study [6]. Some authors suggest that in patients with renal hemosiderosis, the presence of interstitial nephritis (as in the described case) may be a predictor of future renal failure. The level of haptoglobin was shown to be the informative indicator of intravascular hemolysis, a decrease of which correlates with the intensity of hemolysis. The skin and liver biopsies are also performed and show hemosiderin deposits. In addition, in cases of chronic intravascular hemolysis accompanied by kidney disorders, a kidney biopsy is required to exclude, first, the underlying kidney pathology and, second, to predict potential renal failure.

The treatment of mild hemolytic anemia includes iron-containing drugs, folic acid and vitamin B12. There are also reports on the effectiveness of pentoxifylline or betaadrenoceptor blockers in hemolytic anemia. For the treatment of hemolysis in patients with renal hemosiderosis, $\mathrm{N}$ - acetylcysteine is recommended as it reduces oxidative stress. Antioxidant therapy seems reasonable, since there are reports that the incidence of renal failure in patients with renal hemosiderosis is significantly higher when the duration of hemolysis is longer or the degree of iron deposition is greater compared to those who do not have iron deposits in the kidneys.

Thus, in a 32-year-old patient with chronic viral hepatitis $B$ who had suffered from severe alcohol surrogate poisoning, we found the signs of chronic interstitial nephritis with episodes of acute kidney damage, chronic intravascular hemolysis and hemosiderosis of the liver, spleen and kidneys. Given the hepatoand splenomegaly combined with the laboratory signs of severe hypochromic anemia that cannot be explained by the kidney disease, a metabolic disorder of bilirubin with higher levels mainly owing to the indirect 
fraction with normal rates of urea and creatinine, the patient needs in-depth hematological examination, magnetic resonance imaging of the liver, spleen and kidneys in order to eliminate secondary hemochromatosis.

Thus, to prevent such errors when examining a patient with interstitial nephritis of toxic etiology and hemolytic anemia, it is necessary to conduct an in-depth study of iron metabolism, the bone marrow and MRI of the parenchymal organs to exclude secondary hemochromatosis.

We express our gratitude to Nelly L'vova, the doctor of the Department of X-ray Radiology of the multidisciplinary clinic of Tashkent Medical Academy, for her help in describing and preparing the MSCT images.

\section{REFERENCES}

1. Makker J., et al. Dysmetabolic Hyperferritinemia: All Iron Overload Is Not Hemochromatosis. Case Rep Gastroenterol 2015;9:7-142.

2. Hemochromatosis. https://www.nhs.uk/conditions/haemochr omatosis/symptoms/

3. Hemochromatosis. J. L. Porter; P.Rawla. https://www.ncbi.nlm.nih.gov/books/NBK 430862/

4. Calazans LM, de Souza Santos RF, de Souza Gonçalves $M$, et al. Renal hemosiderosis complicating sickle cell anemia. Kidney Int, 2012;81:709.

5. Pardo-Mindán FJ, Diez J, Esparaza N, et al. Renal siderosis in patients with heart-valve prostheses: clinical implications. Nephrol Dial Transplant 1990;5:847-50.
6. Y.L.Manakova,N.P. Domnikova.Tomagnetic resonans tomography in diagnosis of kidney hemosiderosis in patients with paroxysmal nocturnal hemoglobinuria. Bulletin of Russian Academy of Medical Sciences , $M<34$, No. 6, 106-109 $p$ 